\title{
InterCriteria Analysis of rankings of Indian universities
}

\author{
R. Parvathi ${ }^{1}$, Vassia Atanassova ${ }^{2}$, Lyubka Doukovska ${ }^{3}$, \\ C. Yuvapriya ${ }^{1}$ and K. Indhurekha ${ }^{1}$ \\ ${ }^{1}$ Department of Mathematics, Vellalar College for Women, Erode - 638 012, Tamilnadu, India \\ e-mail: paarvathis@rediffmail.com, yuvapriya.c@gmail.com, \\ indhumaths.100@gmail.com \\ ${ }^{2}$ Institute of Biophysics and Biomedical Engineering, Bulgarian Academy of Sciences \\ Acad. Georgi Bonchev Str., Block105, Sofia 1113, Bulgaria \\ e-mail: vassia.atanassova@gmail.com \\ ${ }^{3}$ Institute of Information and Communication Technologies, Bulgarian Academy of Sciences \\ Acad. Georgi Bonchev Str., Block 2, Sofia 1113, Bulgaria \\ e-mail: doukovska@iit.bas.bg
}

Received: 29 September 2017

Accepted: 1 November 2017

\begin{abstract}
The present paper discusses the application of InterCriteria Analysis over a dataset of rankings of the top performing Indian academic institutions in 2017. It serves as an illustrative example for application of the InterCriteria Analysis over weighted data. Comparison is made between the performance of the detected correlations between the different parameters before and after the application of the weight coefficients. All results are interpreted with the intuitionistic fuzzy triangle
\end{abstract}

Keywords: InterCriteria Analysis, Multicriteria decision making, Correlation, Consonance, Dissonance, University ratings.

AMS Classification: 03E72.

\section{Introduction}

InterCriteria Analysis, also known as InterCriteria Decision Making, is an approach that takes an index matrix containing evaluations of objects against a set of criteria as input and calculates the degrees of correlation between each pair of the criteria in the form of intuitionistic fuzzy pairs 
[5]. The method introduced in 2014 by K. Atanassov, D. Mavrov and V. Atanassova [4] is based on the theory of the intuitionistic fuzzy sets [2] and the index matrices [1]. Under this approach, arrays of data obtained by the measurement of many objects against many criteria are processed until correlations are calculated for each pair of criteria in the form of intuitionistic fuzzy pairs of values in the $[0,1]$-interval. The method can be successfully applied to problems, where measuring according to some of the criteria is slower or more expensive, which results in delaying or raising the cost of the overall process of decision making. When solving such problems it is necessary to adopt an approach for reasonable elimination of these criteria, in order to achieve economy and efficiency.

The idea of analyzing the rankings of universities has been explored in several works by Sotirova, Bureva and coauthors, both as general problem statement [16], and as an application to particular datasets for universities of Australia [17], Bulgaria [11, 12], Poland [KRAW], Slovakia [10], United Kingdom [15], employing the results from [3]. Here the InterCriteria Analysis is applied to data about the top performing Indian universities, and here we use the recent legs of ICA theoretical research, employing plotting of the intercriteria pairs onto the interpretational triangle $[7,9]$.

Hence, an attempt has been made to apply InterCriteria Analysis to discuss the parameters involved in the ratings of Universities in India. The purpose is to identify the best correlated indicators and groups of indicators in the Ranking System for the Indian Universities. By applying the approach over the extracted data, we find the parameters that have the highest dependencies. This approach can shed a light on the performance of these educational institutions and of the selected ranking parameters in the evaluation methodology.

\section{Presentation of the input data}

In the present research, we work with a dataset [13] containing the evaluations of 17 Indian universities (in ICA terminology: objects) according to 17 ranking parameters (criteria) for the Year 2017. In addition, we are given the weight coefficients assigned to each of the ranking parameters, which are distributed in five "broad heads" (groups), with 2 to 4 parameters in each group. The ranking parameters and weightages are presented in the following Table 1.

The methodology is developed on the basis of a set of metrics for ranking of academic institutions. Emphasis is placed on identifying data that the institution can easily provide or is easy to obtain from third party sources, and is easily verifiable in the interest of transparency. Some of the parameters' values are calculated according to formulas from primary data provided by the evaluated universities in prescribed formats (1A-1D, 2C, 2D, 3A-3E, 4A-4D, 5D), some are based on data from third party sources $(2 \mathrm{~A}, 2 \mathrm{~B})$ and some contain subjective evaluations collected from the general public through online surveys $(5 \mathrm{~A}-5 \mathrm{C})$. The complete methodology of selecting data and assigning the parameters and their weightages is presented in details in [3]. Here we work with the available data for the universities as evaluated against 17 of the 21 parameters.

Due to data availability and attempt to be representative, we have opted to analyze here the 2017 Top 10 Institutes in Overall Ranking and Top 10 Universities, which (due to some intersection) gives a total number of 17 academic institutions: 
U1: Indian Institute of Science Bangalore

U2: Indian Institute of Technology Madras

U3: Indian Institute of Technology Bombay

U4: Indian Institute of Technology

Kharagpur

U5: Indian Institute of Technology Delhi

U6: Jawaharlal Nehru University, Newdelhi

U7: Indian Institute of Technology Kanpur

U8: Indian Institute of Technology

Guwahati

U9: Indian institute of Technology Roorkee
U10: Banaras Hindu University, Varanasi

U11: Jawaharlal Nehru Centre for

Advanced Scientific Research

(JNCASR), Bengalure

U12: Jadavpur University, Kolkata

U13: Anna University, Chennai

U14: University of Hyderabad

U15: University of Delhi

U16: Amrita Vishwa Vidyapeetham,

Coimbatore

U17: Savitribai Phule Pune University

Table 1. Ranking parameters and weightages of Indian Universities [13]

\begin{tabular}{|c|c|c|c|c|}
\hline \multirow{2}{*}{ No. } & Broad head & \multirow{2}{*}{$\begin{array}{c}\text { Broad } \\
\text { head } \\
\text { weightage }\end{array}$} & \multirow{2}{*}{$\begin{array}{c}\text { Parameter } \\
\text { weightage } \\
\text { in group } \\
\text { (Marks) }\end{array}$} & \multirow{2}{*}{$\begin{array}{c}\text { Total } \\
\text { parameter } \\
\text { weightage }\end{array}$} \\
\hline & Ranking parameter & & & \\
\hline 1 & \multicolumn{4}{|l|}{ Teaching, Learning \& Resources (TLR) } \\
\hline $1 \mathrm{~A}$ & Student Strength including Doctoral Students (SS) & \multirow[t]{4}{*}{0.30} & 20 & 6.0 \\
\hline 1B & $\begin{array}{l}\text { Faculty-student ratio with emphasis on permanent } \\
\text { faculty (FSR) }\end{array}$ & & 30 & 9.0 \\
\hline $1 \mathrm{C}$ & $\begin{array}{l}\text { Combined metric for Faculty with PhD (or } \\
\text { equivalent) and Experience (FQE) }\end{array}$ & & 20 & 6.0 \\
\hline 1D & Financial Resources and their Utilisation (FRU) & & 30 & 9.0 \\
\hline 2 & \multicolumn{4}{|l|}{ Research and Professional Practice (RP) } \\
\hline $2 \mathrm{~A}$ & Combined metric for Publications (PU) & \multirow[t]{4}{*}{0.30} & 35 & 10.5 \\
\hline $2 \mathrm{~B}$ & Combined metric for Quality of Publications (QP) & & 40 & 12.0 \\
\hline $2 \mathrm{C}$ & IPR and Patents: Published and Granted (IPR) & & 15 & 4.5 \\
\hline 2D & $\begin{array}{l}\text { Footprint of Projects, Professional Practice and } \\
\text { Executive Development Programs (FPPP) }\end{array}$ & & 10 & 3.0 \\
\hline 3 & \multicolumn{4}{|l|}{ Graduation Outcomes (G0) } \\
\hline $3 \mathrm{~A}$ & $\begin{array}{l}\text { Combined metric for Placement, Higher Education } \\
\text { and Entrepreneurship (GPHE) }\end{array}$ & \multirow[t]{5}{*}{0.20} & 40 & 8.0 \\
\hline $3 \mathrm{~B}$ & Metric for University Examinations (GUE) & & 15 & 3.0 \\
\hline $3 \mathrm{C}$ & Median Salary (GMS) & & 20 & 4.0 \\
\hline $3 \mathrm{D}$ & $\begin{array}{l}\text { Metric for Graduating Students Admit } \\
\text { ted Into Top Universities (GTOP) }\end{array}$ & & 15 & 3.0 \\
\hline $3 \mathrm{E}$ & $\begin{array}{l}\text { Metric for Number of Ph.D. Students Graduated } \\
\text { (GPHD) }\end{array}$ & & 10 & 2.0 \\
\hline 4 & \multicolumn{4}{|l|}{ Outreach and Inclusivity (OI) } \\
\hline $4 \mathrm{~A}$ & $\begin{array}{l}\text { Percent Students from other states/countries } \\
\text { (Region Diversity RD) }\end{array}$ & 0.10 & 30 & 3.0 \\
\hline
\end{tabular}




\begin{tabular}{|c|c|c|c|c|}
\hline \multirow{2}{*}{ No. } & Broad head & \multirow{2}{*}{$\begin{array}{c}\text { Broad } \\
\text { head } \\
\text { weightage }\end{array}$} & \multirow{2}{*}{$\begin{array}{c}\text { Parameter } \\
\text { weightage } \\
\text { in group } \\
\text { (Marks) }\end{array}$} & \multirow{2}{*}{$\begin{array}{c}\text { Total } \\
\text { parameter } \\
\text { weightage }\end{array}$} \\
\hline & Ranking parameter & & & \\
\hline
\end{tabular}

Contd.

\begin{tabular}{|c|c|c|c|c|}
\hline 4B & Percentage of Women (WD) & & 25 & 2.5 \\
\hline $4 \mathrm{C}$ & $\begin{array}{l}\text { Economically and Socially Challenged Students } \\
\text { (ESCS) }\end{array}$ & & 25 & 2.5 \\
\hline 4D & Facilities for Physically Challenged Students (PCS) & & 20 & 2.0 \\
\hline 5 & \multicolumn{4}{|l|}{ Perception (PR) } \\
\hline $5 \mathrm{~A}$ & $\begin{array}{l}\text { Peer Perception: Employers and Research } \\
\text { Investors (PREMP) }\end{array}$ & 0.10 & 25 & 2.5 \\
\hline $5 B$ & Peer Perception: Academic Peers (PRACD) & & 25 & 2.5 \\
\hline $5 \mathrm{C}$ & Public Perception (PRPUB) & & 25 & 2.5 \\
\hline $5 \mathrm{D}$ & Competitiveness (PRCMP) & & 25 & 2.5 \\
\hline
\end{tabular}

The input dataset for the ICA analysis, as extracted from [13] (pp. 32-41) is given in Table 2.

Table 2. Evaluation of the 17 top ranking Indian universities, against 17 ranking parameters

\begin{tabular}{|c|c|c|c|c|c|c|c|c|c|c|c|c|c|c|c|c|c|}
\hline & \multicolumn{4}{|c|}{ TLR } & \multicolumn{4}{|c|}{ RP } & \multicolumn{2}{|c|}{ GO } & \multicolumn{4}{|c|}{ 이 } & \multicolumn{3}{|c|}{ PR } \\
\hline & SS & FSR & FQE & FRU & PU & $Q P$ & \begin{tabular}{|l|} 
IPR \\
\end{tabular} & FPPP & GUE & GPHD & RD & WD & ESCS & PCS & PREMP & PRACD & PRPUB \\
\hline U01 & 11.00 & 30.00 & 18.03 & 24.07 & 35.00 & 40.00 & 9.20 & 3.39 & 60.00 & \begin{tabular}{|l|l} 
& 27.97
\end{tabular} & 21.46 & 13.68 & 16.34 & 10.00 & 22.83 & 50.00 & 10.50 \\
\hline U02 & 17.00 & 19.09 & 13.37 & 20.03 & 24.77 & 31.59 & 9.11 & 7.13 & 60.00 & 24.02 & 21.25 & 13.00 & 25.00 & 17.50 & 21.91 & 37.08 & 9.63 \\
\hline U03 & 17.00 & 19.79 & 13.44 & 14.45 & 25.95 & 35.61 & 11.35 & 5.24 & 45.84 & 24.23 & 20.42 & 12.88 & 25.00 & 7.50 & 25.00 & 45.37 & 13.07 \\
\hline U04 & 16.14 & 15.91 & 11.17 & 11.85 & 24.86 & 35.87 & 4.86 & 4.87 & 58.37 & 26.74 & 18.91 & $\mid 11.13$ & 22.81 & 20.00 & 20.59 & 36.00 & 8.13 \\
\hline U05 & 14.67 & 15.92 & 11.16 & 13.70 & 25.38 & 33.11 & 6.02 & 3.97 & 46.04 & 19.88 & 21.95 & $\mid 12.82$ & 21.42 & 12.50 & 23.22 & 37.36 & 8.95 \\
\hline U06 & 13.40 & 21.72 & 13.74 & 13.24 & 13.04 & 19.22 & 0.64 & 1.06 & 60.00 & 38.71 & 22.49 & 24.91 & 25.00 & 10.00 & 11.69 & 33.10 & 2.48 \\
\hline U07 & 15.04 & 17.81 & 12.42 & 14.80 & 22.69 & 29.27 & 7.15 & 3.02 & 39.20 & 19.14 & 18.97 & 7.93 & 23.11 & 10.00 & 14.72 & 40.41 & 8.49 \\
\hline U08 & 12.62 & 22.40 & 14.98 & 15.53 & 20.19 & 25.81 & 0.19 & 1.28 & 60.00 & 18.28 & 21.96 & 12.32 & 25.00 & 20.00 & 7.41 & 17.83 & 3.56 \\
\hline U09 & 15.32 & 14.90 & 10.45 & 11.58 & 21.86 & 30.36 & 0.53 & 3.85 & 60.00 & 23.38 & 23.70 & 11.51 & 25.00 & 12.50 & 10.45 & 17.83 & 4.11 \\
\hline U10 & 19.00 & 12.06 & 7.26 & 9.54 & 15.44 & 30.51 & 0.31 & 3.71 & 60.00 & 34.36 & 6.83 & 16.15 & 25.00 & 15.00 & 12.80 & 27.60 & 3.61 \\
\hline U11 & 2.00 & 30.00 & 17.24 & 29.04 & 25.83 & 20.07 & 4.89 & 1.14 & 60.00 & 8.79 & 22.82 & 20.52 & 1.60 & 2.50 & 0.00 & 6.28 & 0.64 \\
\hline U12 & 18.05 & 14.58 & 9.61 & 6.40 & 20.63 & 29.91 & \begin{tabular}{|l}
1.62 \\
\end{tabular} & 2.20 & 58.40 & 33.02 & 4.14 & 17.57 & 14.16 & 17.50 & 5.47 & 21.95 & 1.39 \\
\hline U13 & 15.99 & 14.60 & 8.33 & 7.33 & 22.18 & 28.01 & 2.42 & 1.97 & 60.00 & 19.31 & 2.00 & 23.01 & 25.00 & 10.00 & 13.80 & 15.82 & 14.32 \\
\hline U14 & 11.16 & 21.90 & 14.42 & 9.83 & 18.37 & 22.71 & 0.60 & 1.09 & 57.54 & 21.25 & 12.03 & 21.10 & 25.00 & 20.00 & 3.09 & 23.09 & 0.88 \\
\hline U15 & 17.11 & 10.65 & 6.80 & 8.91 & 17.48 & 33.47 & 2.30 & 3.37 & 42.06 & 40.00 & 5.20 & 20.08 & 13.32 & 20.00 & 3.09 & 25.72 & 1.95 \\
\hline U16 & 15.50 & 24.93 & 10.65 & 11.82 & 9.17 & 17.62 & 7.59 & 5.11 & 60.00 & 5.77 & 12.97 & 24.20 & 25.00 & 20.00 & 7.41 & 8.64 & 10.08 \\
\hline U17 & 14.12 & 16.16 & 10.04 & 16.08 & 13.56 & 18.14 & 0.44 & 2.90 & 60.00 & 25.13 & 4.23 & 23.03 & 325.00 & 20.00 & 0.00 & 7.49 & 3.71 \\
\hline Marks & 20 & 30 & 20 & 30 & 35 & 40 & 15 & 10 & 60 & 40 & 30 & 25 & 25 & 20 & 25 & 50 & 25 \\
\hline Weight & & 0.3 & & & & 0 & .3 & & & .2 & & & 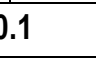 & & & 0.1 & \\
\hline
\end{tabular}

For each of the evaluated 17 universities, the aggregated evaluation per broad head is given in Table 3, where the weightages of the broad heads are as given in both Table 1 and 2 . 
Table 3. Aggregated parameters and weightages for the top 17 Indian universities [13]

\begin{tabular}{|c|c|c|c|c|c|}
\hline & TLR (0.30) & RP (0.30) & G0 (0.20) & Ol (0.10) & PR (0.10) \\
\hline U01 & 83.11 & 87.59 & 87.97 & 61.48 & 83.33 \\
\hline U02 & 69.49 & 72.60 & 84.02 & 76.75 & 68.7 \\
\hline U03 & 64.68 & 78.14 & 70.07 & 65.80 & 83.44 \\
\hline U04 & 55.07 & 70.46 & 85.11 & 72.85 & 64.72 \\
\hline U05 & 55.45 & 68.48 & 65.92 & 68.69 & 69.53 \\
\hline U06 & 62.11 & 33.96 & 98.71 & 82.40 & 47.27 \\
\hline U07 & 60.07 & 62.14 & 58.34 & 60.01 & 63.62 \\
\hline U08 & 65.53 & 47.46 & 78.28 & 79.28 & 28.79 \\
\hline U09 & 52.24 & 56.60 & 83.38 & 72.70 & 32.38 \\
\hline U10 & 47.85 & 49.96 & 94.36 & 62.97 & 44.01 \\
\hline U11 & 78.28 & 51.93 & 68.97 & 47.44 & 6.92 \\
\hline U12 & 48.64 & 54.09 & 91.42 & 53.37 & 28.81 \\
\hline U13 & 46.25 & 54.58 & 79.31 & 60.01 & 43.94 \\
\hline U14 & 57.30 & 42.77 & 78.79 & 78.13 & 27.06 \\
\hline U15 & 43.48 & 56.61 & 82.06 & 58.6 & 30.76 \\
\hline U16 & 62.90 & 39.49 & 65.77 & 82.17 & 26.12 \\
\hline U17 & 56.39 & 35.03 & 85.13 & 72.26 & 11.20 \\
\hline
\end{tabular}

\section{Results of application of ICA}

From the application of ICA on the aggregated data, we obtain the following output, giving the pairwise correlations between the different broad heads of parameters on the basis of the Top 17 academic institutions: Table 4(a), (b), Figure 1.

\begin{tabular}{|c|c|c|c|c|c|}
\hline$\mu$ & TLR & RP & GO & Ol & PR \\
\hline TLR & 1 & 0.551471 & 0.426471 & 0.602941 & 0.544118 \\
\hline RP & 0.551471 & 1 & 0.463235 & 0.389706 & 0.816176 \\
\hline GO & 0.426471 & 0.463235 & 1 & 0.492647 & 0.558824 \\
\hline Ol & 0.602941 & 0.389706 & 0.492647 & 1 & 0.514706 \\
\hline PR & 0.544118 & 0.816176 & 0.558824 & 0.514706 & 1 \\
\hline
\end{tabular}

\begin{tabular}{|c|c|c|c|c|c|}
\hline $\mathrm{v}$ & $\mathrm{TLR}$ & $\mathrm{RP}$ & $\mathrm{GO}$ & $\mathrm{OI}$ & $\mathrm{PR}$ \\
\hline $\mathrm{TLR}$ & 0 & 0.448529 & 0.573529 & 0.389706 & 0.455882 \\
\hline $\mathrm{RP}$ & 0.448529 & 0 & 0.536765 & 0.602941 & 0.183824 \\
\hline $\mathrm{GO}$ & 0.573529 & 0.536765 & 0 & 0.5 & 0.441176 \\
\hline $\mathrm{Ol}$ & 0.389706 & 0.602941 & 0.5 & 0 & 0.477941 \\
\hline $\mathrm{PR}$ & 0.455882 & 0.183824 & 0.441176 & 0.477941 & 0 \\
\hline
\end{tabular}

Table 4. ICA analysis of the groups (broad heads) of parameters, based on the data for the top 17 Indian universities in 2017.

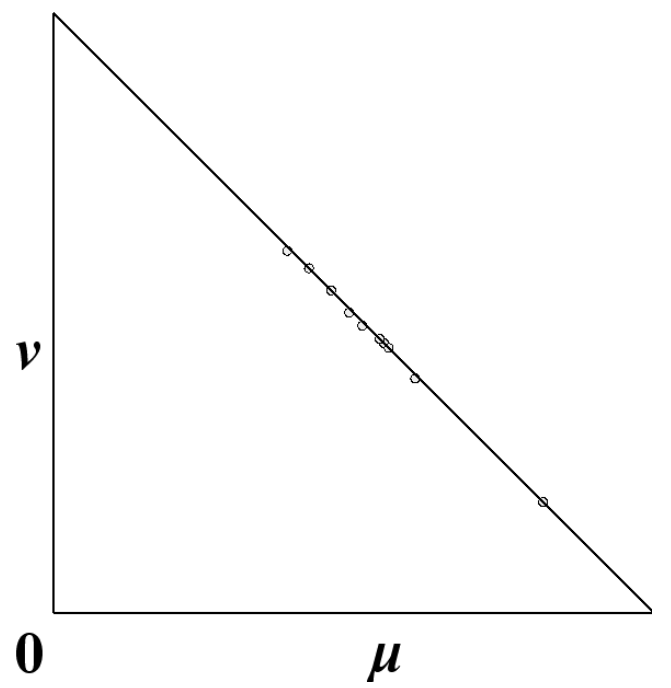

Figure 1. Results from Table 4 (left), plotted as points onto the intuitionistic fuzzy triangle 
The results show that the strongest detected correlation is between the Perception (PR) and Research and Professional Practice (RP), as given by the pair $\langle 0.816176,0.183824\rangle$ and the lowest one is between Research and Professional Practice (RP) and Outreach and Inclusivity (OI), as given by the pair $\langle 0.389706,0.602941\rangle$. All the rest intercriteria pairs exhibit high dissonance with practically zero uncertainty, which means that the evaluated group of academic institutions exhibit a whole spectrum of different performances.

We continue with the analysis of the detailed data of all analyzed institutions against all ranking parameters, given in Table 2. The output is given in Table 5 (a) and (b) and Figure 4.

Table 5. Results from the application of ICA over the input data from Table 2.

\begin{tabular}{|c|c|c|c|c|c|c|c|c|c|c|c|c|c|c|c|c|c|}
\hline$\mu$ & SS & FSR & FQE & FRU & PU & QP & IPR & FPPP & GUE & GPHD & RD & WD & ESCS & PCS & PREMP & PRACD & PRPUB \\
\hline SS & 1.000 & 0.191 & 0.221 & 0.279 & 0.441 & 0.618 & 0.515 & 0.691 & 0.250 & 0.654 & 0.316 & 0.456 & 0.368 & 0.471 & 0.574 & 0.551 & 0.581 \\
\hline FSR & 0.191 & 1.000 & 0.897 & 0.765 & 0.588 & 0.382 & 0.632 & 0.463 & 0.426 & 0.301 & 0.684 & 0.544 & 0.368 & 0.338 & 0.500 & 0.485 & 0.537 \\
\hline FQE & 0.221 & 0.897 & 1.000 & 0.772 & 0.662 & 0.485 & 0.618 & 0.478 & 0.368 & 0.375 & 0.750 & 0.463 & 0.338 & 0.309 & 0.551 & 0.574 & 0.507 \\
\hline FRU & 0.279 & 0.765 & 0.772 & 1.000 & 0.654 & 0.493 & 0.625 & 0.544 & 0.390 & 0.397 & 0.743 & 0.456 & 0.301 & 0.309 & 0.559 & 0.581 & 0.574 \\
\hline PU & 0.441 & 0.588 & 0.662 & 0.654 & 1.000 & 0.765 & 0.735 & 0.610 & 0.257 & 0.449 & 0.618 & 0.301 & 0.184 & 0.213 & 0.743 & 0.654 & 0.625 \\
\hline QP & 0.618 & 0.382 & 0.485 & 0.493 & 0.765 & 1.000 & 0.632 & 0.728 & 0.213 & 0.684 & 0.515 & 0.272 & 0.213 & 0.375 & 0.750 & 0.772 & 0.625 \\
\hline IPR & 0.515 & 0.632 & 0.618 & 0.625 & 0.735 & 0.632 & 1.000 & 0.699 & 0.235 & 0.434 & 0.544 & 0.449 & 0.250 & 0.265 & 0.713 & 0.699 & 0.728 \\
\hline FPPP & 0.691 & 0.463 & 0.478 & 0.544 & 0.610 & 0.728 & 0.699 & 1.000 & 0.294 & 0.500 & 0.537 & 0.338 & 0.375 & 0.449 & 0.699 & 0.632 & 0.750 \\
\hline GUE & 0.250 & 0.426 & 0.368 & 0.390 & 0.257 & 0.213 & 0.235 & 0.294 & 1.000 & 0.309 & 0.397 & 0.456 & 0.581 & 0.301 & 0.287 & 0.169 & 0.346 \\
\hline GPHD & 0.654 & 0.301 & 0.375 & 0.397 & 0.449 & 0.684 & 0.434 & 0.500 & 0.309 & 1.000 & 0.404 & 0.559 & 0.272 & 0.456 & 0.515 & 0.618 & 0.426 \\
\hline RD & 0.316 & 0.684 & 0.750 & 0.743 & 0.618 & 0.515 & 0.544 & 0.537 & 0.397 & 0.404 & 1.000 & 0.375 & 0.324 & 0.287 & 0.581 & 0.581 & 0.478 \\
\hline WD & 0.456 & 0.544 & 0.463 & 0.456 & 0.301 & 0.272 & 0.449 & 0.338 & 0.456 & 0.559 & 0.375 & 1.000 & 0.360 & 0.456 & 0.309 & 0.316 & 0.426 \\
\hline ESCS & 0.368 & 0.368 & 0.338 & 0.301 & 0.184 & 0.213 & 0.250 & 0.375 & 0.581 & 0.272 & 0.324 & 0.360 & 1.000 & 0.375 & 0.353 & 0.294 & 0.419 \\
\hline PCS & 0.471 & 0.338 & 0.309 & 0.309 & 0.213 & 0.375 & 0.265 & 0.449 & 0.301 & 0.456 & 0.287 & 0.456 & 0.375 & 1.000 & 0.265 & 0.294 & 0.316 \\
\hline PREMP & 0.574 & 0.500 & 0.551 & 0.559 & 0.743 & 0.750 & 0.713 & 0.699 & 0.287 & 0.515 & 0.581 & 0.309 & 0.353 & 0.265 & 1.000 & 0.794 & 0.787 \\
\hline PRACD & 0.551 & 0.485 & 0.574 & 0.581 & 0.654 & 0.772 & 0.699 & 0.632 & 0.169 & 0.618 & 0.581 & 0.316 & 0.294 & 0.294 & 0.794 & 1.000 & 0.662 \\
\hline PRPUB & 0.581 & 0.537 & 0.507 & 0.574 & 0.625 & 0.625 & 0.728 & 0.750 & 0.346 & 0.426 & 0.478 & 0.426 & 0.419 & 0.316 & 0.787 & 0.662 & 1.000 \\
\hline
\end{tabular}

\begin{tabular}{|c|c|c|c|c|c|c|c|c|c|c|c|c|c|c|c|c|c|}
\hline v & SS & FSR & FQE & FRU & PU & QP & IPR & FPPP & GUE & GPHD & RD & WD & ESCS & PCS & PREMP & PRACD & PRPUB \\
\hline SS & 0.000 & 0.794 & 772 & 0.713 & 551 & 0.375 & 478 & 0.301 & 0.412 & 0.338 & 0.676 & 0.537 & 0.309 & 0.353 & 0.397 & 0.434 & 0.412 \\
\hline FSR & 0.794 & 0.000 & 0.096 & 0.228 & 0.404 & 0.610 & 0.360 & 0.529 & 0.250 & 0.691 & 0.309 & 0.449 & 0.294 & 0.485 & 0.471 & 0.500 & 0.456 \\
\hline FQE & 0.772 & 0.096 & 0.000 & 0.228 & 0.338 & 0.515 & 0.382 & 0.522 & 0.301 & 0.625 & 0.250 & 0.537 & 0.331 & 0.522 & 0.426 & 0.419 & 0.493 \\
\hline FRU & 0.713 & 0.228 & 0.228 & 0.000 & 0.346 & 0.507 & 0.375 & 0.456 & 0.279 & 0.603 & 0.257 & 0.544 & 0.368 & 0.522 & 0.419 & 0.412 & 0.426 \\
\hline PU & 0.551 & 0.404 & 0.338 & 0.346 & 0.000 & 0.235 & 0.265 & 0.390 & 0.412 & 0.551 & 0.382 & 0.699 & 0.485 & 0.618 & 0.235 & 0.338 & 0.375 \\
\hline QP & 0.375 & 0.610 & 0.515 & 0.507 & 0.235 & 0.000 & 0.368 & 0.272 & 0.456 & 0.316 & 0.485 & 0.728 & 0.456 & 0.456 & 0.228 & 0.221 & 0.375 \\
\hline IPR & 0.478 & 0.360 & 0.382 & 0.375 & 0.265 & 0.368 & 0.000 & 0.301 & 0.434 & 0.566 & 0.456 & 0.551 & 0.419 & 0.566 & 0.265 & 0.294 & 0.272 \\
\hline FPPP & 0.301 & 0.529 & 0.522 & 0.456 & 0.390 & 0.272 & 0.301 & 0.000 & 0.375 & 0.500 & 0.463 & 0.662 & 0.294 & 0.382 & 0.279 & 0.360 & 0.250 \\
\hline GUE & 0.412 & 0.250 & 0.301 & 0.279 & 0.412 & 0.456 & 0.434 & 0.375 & 0.000 & 0.360 & 0.272 & 0.213 & 0.169 & 0.287 & 0.390 & 0.507 & 0.324 \\
\hline GPHD & 0.338 & 0.691 & 0.625 & 0.603 & 0.551 & 0.316 & 0.566 & 0.500 & 0.360 & 0.000 & 0.596 & 0.441 & 0.397 & 0.375 & 0.463 & 0.375 & 0.574 \\
\hline RD & 0.676 & 0.309 & 0.250 & 0.257 & 0.382 & 0.485 & 0.456 & 0.463 & 0.272 & 0.596 & 0.000 & 0.625 & 0.346 & 0.544 & 0.397 & 0.412 & 0.522 \\
\hline WD & 0.537 & 0.449 & 0.537 & 0.544 & 0.699 & 0.728 & 0.551 & 0.662 & 0.213 & 0.441 & 0.625 & 0.000 & 0.309 & 0.375 & 0.669 & 0.676 & 0.574 \\
\hline ESCS & 0.309 & 0.294 & 0.331 & 0.368 & 0.485 & 0.456 & 0.419 & 0.294 & 0.169 & 0.397 & 0.346 & 0.309 & 0.000 & 0.228 & 0.309 & 0.382 & 0.250 \\
\hline PCS & 0.353 & 0.485 & 0.522 & 0.522 & 0.618 & 0.456 & 0.566 & 0.382 & 0.287 & 0.375 & 0.544 & 0.375 & 0.228 & 0.000 & 0.574 & 0.529 & 0.515 \\
\hline PREMP & 0.397 & 0.471 & 0.426 & 0.419 & 0.235 & 0.228 & 0.265 & 0.279 & 0.390 & 0.463 & 0.397 & 0.669 & 0.309 & 0.574 & 0.000 & 0.176 & 0.191 \\
\hline PRACD & 0.434 & 0.500 & 0.419 & 0.412 & 0.338 & 0.221 & 0.294 & 0.360 & 0.507 & 0.375 & 0.412 & 0.676 & 0.382 & 0.529 & 0.176 & 0.000 & 0.331 \\
\hline PRPUB & 0.412 & 0.456 & 0.493 & 0.426 & 0.375 & 0.375 & 0.272 & 0.250 & 0.324 & 0.574 & 0.522 & 0.574 & 0.250 & 0.515 & 0.191 & 0.331 & 0.000 \\
\hline
\end{tabular}




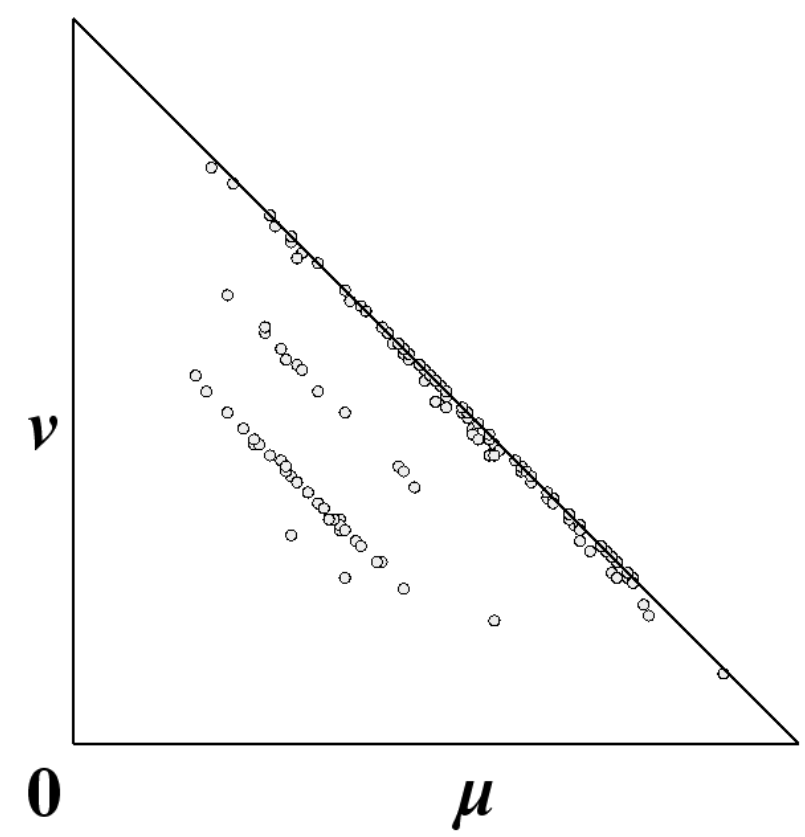

Figure 2. Results from the application of ICA (Table 5)

plotted onto the intuitionistic fuzzy interpretational triangle

The figure shows the resultant intuitionistic fuzzy set, visibly clustered in several subsets that are worth analyzing on their own. It is also worth discussing the broad heads of parameters on the level of intercriteria pairs between the parameters in each head.

For the first broad head Teaching, Learning \& Resources (TLR) comprising of the four criteria Student Strength including Doctoral Students (SS), Faculty-student ratio with emphasis on permanent faculty (FSR), Combined metric for Faculty with PhD (or equivalent) and Experience (FQE) and Financial Resources and their Utilisation (FRU) we note the strong bonds within the set of parameters FSR, FQE and FRU. The most obviously correlated parameters here, FSR and FQE, exhibit the strongest consonance of $\langle 0.897,0.096\rangle$ and FRU correlates with both of them with almost equal extent. The students' strength (SS) does not correlate with these three criteria in the broad head TLR at all.

In the second broad head, Research and Professional Practice (RP) the four parameters in the group - Combined metric for Publications (PU), Combined metric for Quality of Publications (QP), IPR and Patents: Published and Granted (IPR), Footprint of Projects, Professional Practice and Executive Development Programs (FPPP) - exhibit relatively strong consonances.

Equally strong bonds are there between the three parameters in the broad head Perception (PR): Peer Perception: Employers and Research Investors (PREMP), Peer Perception: Academic Peers (PRACD) and Public Perception (PRPUB). These three parameters are particularly notable since according to the methodology of collecting the input data, these are subjective evaluations (perceptions) collected from the public through online surveys.

The third broad head, Graduation Outcomes (GO) consisting of the two parameters Metric for University Examinations (GUE) and Metric for Number of Ph.D. Students Graduated (GPHD) exhibit only one intercriteria pair $\langle 0.309,0.360\rangle$, i.e. dissonance, with all the three measures, of membership, non-membership and uncertainty being almost equal. 
Similar is the situation with the parameters in the fourth broad head Outreach and Inclusivity (OI), which consists of Percent Students from other states/countries (Region Diversity RD), Percentage of Women (WD), Economically and Socially Challenged Students (ESCS) and Facilities for Physically Challenged Students (PCS), where all the pairs are from dissonance to weak negative consonance.

We will now analyze the intercriteria pairs independently, both within and across the so formed broad heads. We have three visibly well-formed clusters of points and several isolated points. The analysis shows that the middle cluster of points is fully formed by the intercriteria pairs, where one of the criteria is parameter Facilities for Physically Challenged Students (PCS), as illustrated on Figure 3. The cluster closest to the uncertainty (point $(0,0)$ of the IF triangle, see Figure 4) is formed by the criteria Metric for University Examinations (GUE) and Economically and Socially Challenged Students (ESCS).

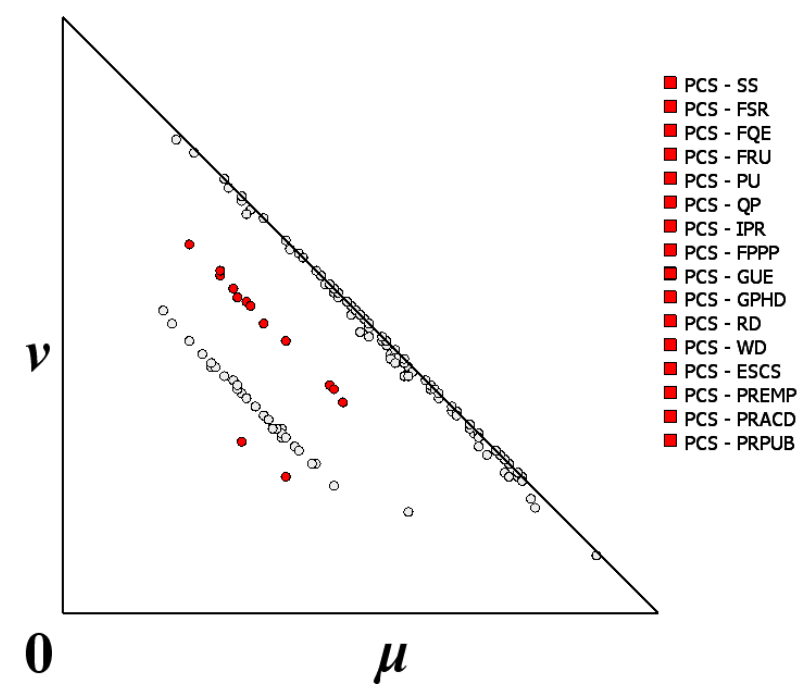

Figure 4. Selection of the intercriteria pairs with parameter PCS.

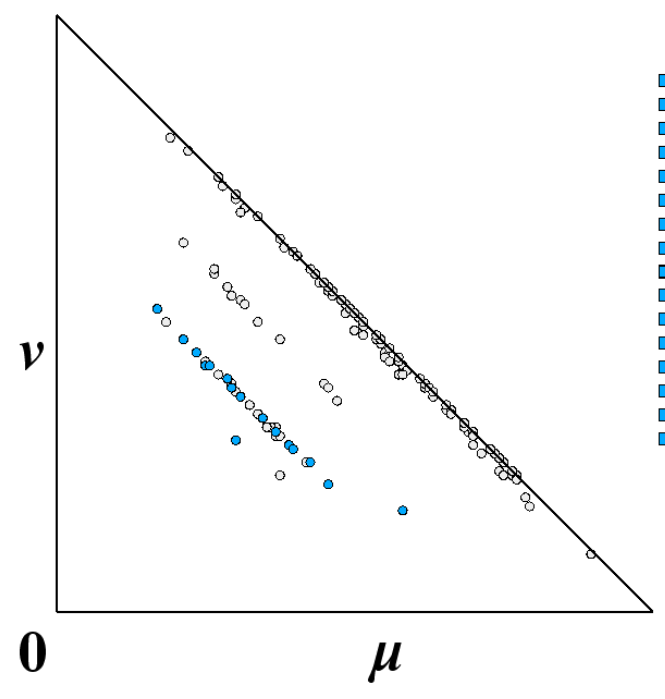

(a)

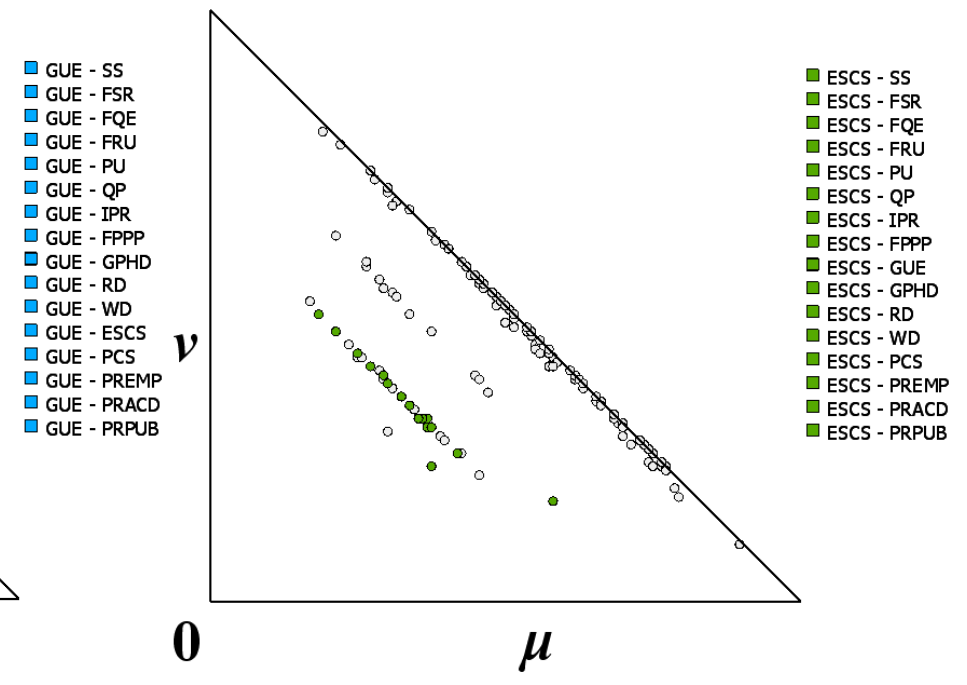

(b)

Figure 5. Selection of the intercriteria pairs with parameter GUE (a) and ESCS (b).

If analyzed in a pairwise manner, between the 17 parameters there exist 136 intercriteria pairs, and the strongest detected correlations is between parameters Faculty-student ratio with 
emphasis on permanent faculty (FSR) and Combined metric for Faculty with PhD (or equivalent) and Experience (FQE) - $\langle 0.897,0.096\rangle$, which is both the point closest to the Truth $(1,0)$, and the point with the highest $\mu / v$ ratio (see [8]). From the rest, the top approx. 10\% pairs (15) range from the above mentioned pair $\langle 0.897,0.096\rangle$ down to two pairs with equal values $\langle 0.728,0.272\rangle$ standing for the correlations between Combined metric for Quality of Publications (QP) and Footprint of Projects, Professional Practice and Executive Development Programs (FPPP), and between IPR and Patents: Published and Granted (IPR) and Public Perception (PRPUB). The rest of the top correlating pairs is given in Table 6, where the columns stay for, respectively, the pair of criteria, the membership and the non-membership values $\mu$ and $v$ of the intercriteria pair, the distance $d$ from Truth per [7] and the additionally informative ratio $\mu / v$ per [8].

Table 6. Top 10\% (15) and Bottom 10\% (14) correlating intercriteria pairs.

\begin{tabular}{|c|c|c|c|c|c|}
\hline C1 & C2 & $\mu$ & $v$ & $d$ & $\mu / v$ \\
\hline FSR & FQE & 0.897 & 0.096 & 0.141 & 9.385 \\
\hline PREMP & PRACD & 0.7941 & 0.1765 & 0.2712 & 4.5 \\
\hline PREMP & PRPUB & 0.7868 & 0.1912 & 0.2864 & 4.1154 \\
\hline QP & PRACD & 0.7721 & 0.2206 & 0.3172 & 3.5 \\
\hline FQE & FRU & 0.7721 & 0.2279 & 0.3224 & 3.3871 \\
\hline FSR & FRU & 0.765 & 0.228 & 0.328 & 3.355 \\
\hline PU & QP & 0.7647 & 0.2353 & 0.3328 & 3.25 \\
\hline QP & PREMP & 0.75 & 0.2279 & 0.3383 & 3.2903 \\
\hline PU & PREMP & 0.7426 & 0.2353 & 0.3487 & 3.1563 \\
\hline FQE & RD & 0.75 & 0.25 & 0.3536 & 3 \\
\hline FPPP & PRPUB & 0.75 & 0.25 & 0.3536 & 3 \\
\hline FRU & RD & 0.7426 & 0.2574 & 0.364 & 2.8857 \\
\hline PU & IPR & 0.7353 & 0.2647 & 0.3744 & 2.7778 \\
\hline QP & FPPP & 0.7279 & 0.2721 & 0.3847 & 2.6757 \\
\hline IPR & PRPUB & 0.7279 & 0.2721 & 0.3847 & 2.6757 \\
\hline
\end{tabular}

\begin{tabular}{|c|c|c|c|c|c|}
\hline PCS & PREMP & 0.2647 & 0.5735 & 0.9325 & 0.4615 \\
\hline FPPP & WD & 0.3382 & 0.6618 & 0.9359 & 0.5111 \\
\hline PU & ESCS & 0.1838 & 0.4853 & 0.9496 & 0.3788 \\
\hline WD & PRACD & 0.3162 & 0.6765 & 0.9619 & 0.4674 \\
\hline SS & RD & 0.316 & 0.677 & 0.962 & 0.467 \\
\hline WD & PREMP & 0.3088 & 0.6691 & 0.962 & 0.4615 \\
\hline GUE & PRACD & 0.1691 & 0.5074 & 0.9735 & 0.3333 \\
\hline FSR & GPHD & 0.3015 & 0.6912 & 0.9827 & 0.4362 \\
\hline PU & WD & 0.3015 & 0.6985 & 0.9879 & 0.4316 \\
\hline PU & PCS & 0.2132 & 0.6176 & 1.0002 & 0.3452 \\
\hline SS & FRU & 0.279 & 0.713 & 1.014 & 0.392 \\
\hline QP & WD & 0.2721 & 0.7279 & 1.0295 & 0.3737 \\
\hline SS & FQE & 0.221 & 0.772 & 1.097 & 0.286 \\
\hline SS & FSR & 0.191 & 0.794 & 1.134 & 0.241 \\
\hline
\end{tabular}




\section{Conclusions}

The present paper is dedicated to application of the recently proposed method of Intercriteria Analysis that aims to detect dependencies between criteria on the basis of the evaluations of objects against them. After successful application of the method over datasets with rankings of academic institutions and universities in Australia, Bulgaria, Slovakia and United Kingdom, in this current leg of research we have applied the method over a dataset about the best performing universities in India in 2017, as excerpted from the National Institutional Ranking Framework Methodology for Ranking of Academic Institutions in India. Findings about the top correlating among the 17 parameters, and among the groups of criteria have been presented and discussed.

\section{Acknowledgements}

The Indian coauthors would like to thank University Grants Commission, New Delhi, India for its financial support to the Major Research Project F. No: MRP - 43 - 418/2014 (SR) dated September 2015.

The Bulgarian coauthors would like to thank the National Science Fund of Bulgaria for its financial support under Grant Ref. No. DFNI-I-02-5/2016 "InterCriteria Analysis: A Novel Approach to Decision Making" and Grant DFNP-17-136/2017 under the Program for career development of young scientists, Bulgarian Academy of Sciences.

\section{References}

[1] Atanassov, K. (2014) Index Matrices: Towards an Augumented Matrix Calculus, Studies in Computational Intelligence Series, Vol. 573, Springer, Cham.

[2] Atanassov, K. (1986) Intuitionistic fuzzy sets, Fuzzy Sets and Systems, 20(1), 87-96.

[3] Atanassov, K., Atanassova, V., \& Gluhchev, G. (2015) InterCriteria Analysis: Ideas and problems, Notes on Intuitionistic Fuzzy Sets, 21(1), 81-88.

[4] Atanassov, K., Mavrov, D., \& Atanassova, V. (2014) Intercriteria Decision Making: A New Approach for Multicriteria Decision Making, Based on Index Matrices and Intuitionistic Fuzzy Sets. Issues in Intuitionistic Fuzzy Sets and Generalized Nets, 11, 1-8.

[5] Atanassov, K., Szmidt, E. \& Kacprzyk, J. (2013) On intuitionistic fuzzy pairs, Notes on Intuitionistic Fuzzy Sets, 19(3), 1-13.

[6] Atanassova, V., Mavrov, D., Doukovska, L., \& Atanassov, K. (2014) Discussion on the threshold values in the InterCriteria Decision Making approach. Notes on Intuitionistic Fuzzy Sets, 20(2), 94-99.

[7] Atanassova, V. (2015) Interpretation in the Intuitionistic Fuzzy Triangle of the Results, Obtained by the InterCriteria Analysis. Proc. of 16th World Congress of the International Fuzzy Systems Association (IFSA), 9th Conference of the European Society for Fuzzy Logic and Technology (EUSFLAT), 30. 06-03. 07. 2015, Gijon, Spain, 2015, 1369-1374. 
[8] Atanassova, V. (2017) New Modified Level Operator $N \gamma$ over Intuitionistic Fuzzy Sets. In: Henning Christiansen, Hélène Jaudoin, Panagiotis Chountas, Troels Andreasen, Henrik Legind Larsen (Eds.): Flexible Query Answering Systems, 12th International Conference, FQAS 2017, London, UK, June 21-22, 2017. Proceedings. Lecture Notes in Computer Science 10333, Springer, 209-214.

[9] Atanassova, V., Vardeva, L., Sotirova, E., \& Doukovska, L. (2016) Traversing and ranking of elements of an intuitionistic fuzzy set in the intuitionistic fuzzy interpretation triangle, Chapter, Novel Developments in Uncertainty Representation and Processing, Vol. 401, Advances in Intelligent Systems and Computing, Springer, 161-174.

[10] Bureva, V., Michalíková, A., Sotirova, E., Popov, S., Riečan, B., \& Roeva, O. (2017) Application of the InterCriteria Analysis to the universities rankings system in the Slovak Republic. Notes on Intuitionistic Fuzzy Sets, 23(2), 128-140.

[11] Bureva, V., Sotirova, E., \& Panayotov, H. (2015/2016) The intercriteria decision making method to Bulgarian university ranking system, Annual of "Informatics" Section Union of Scientists in Bulgaria, 8, 54-71.

[12] Bureva, V., Sotirova, E., Sotirov, S., \& Mavrov, D. (2015) Application of the InterCriteria decision making method to Bulgarian universities ranking. Notes on Intuitionistic Fuzzy Sets, 21(2), 111-117.

[13] India Rankings 2017. National Institutional Ranking Framework Methodology for Ranking of Academic Institutions in India, Ministry of Human Resource Development. Available online: https://www.nirfindia.org/Docs/Ranking_Methodology_And_ Metrics_2017.pdf

[14] Krawczak, M., Bureva, V., Sotirova, E., \& Szmidt, E. (2016) Application of the InterCriteria Decision Making Method to Universities Ranking. In: Atanassov, K. et al. (eds) Novel Developments in Uncertainty Representation and Processing. Advances in Intelligent Systems and Computing, vol 401. Springer, Cham, doi: 10.1007/978-3-319-26211-6_31.

[15] Sotirova, E., Bureva, V., Chountas, P., \& Krawczak, M. (2016) An application of intercriteria decision making method to the rankings of universities in the United Kingdom. Notes on Intuitionistic Fuzzy Sets, 22(3), 112-119.

[16] Sotirova, E., Bureva V., \& Sotirov S. (2016) A Generalized Net Model for Evaluation Process Using InterCriteria Analysis Method in the University. In: Angelov P., Sotirov S. (eds) Imprecision and Uncertainty in Information Representation and Processing. Studies in Fuzziness and Soft Computing, Vol 332. Springer, Cham, doi: 10.1007/978-3-31926302-1_23.

[17] Sotirova, E., \& Shannon, A. (2015) Application of intercriteria analysis to the rankings of Australian universities. Notes on Intuitionistic Fuzzy Sets, 21(4), 136-142. 